\title{
Construction of College Students' Physical Health Data Sharing System Based on Django Framework
}

\author{
Hui-chao Li and Shun-fa Shen \\ Department of Physical Education, Civil Aviation University of China, Tianjin 300300, China \\ Correspondence should be addressed to Shun-fa Shen; laoliu329@163.com
}

Received 29 July 2021; Revised 13 September 2021; Accepted 4 October 2021; Published 1 November 2021

Academic Editor: Mu Zhou

Copyright (c) 2021 Hui-chao Li and Shun-fa Shen. This is an open access article distributed under the Creative Commons Attribution License, which permits unrestricted use, distribution, and reproduction in any medium, provided the original work is properly cited.

In view of the current situation of college students' physical health affected by the learning environment and living environment, which leads to the low level of students' physical health and the lack of understanding of students' physical health, this paper puts forward the construction of college students' physical health data sharing system based on Django framework. By analyzing the feasibility of constructing the data sharing system of college students' physical health, this paper constructs the organizational framework of the data sharing system of college students' physical health and constructs the data sharing system of college students' physical health according to the implementation process of the data sharing system of college students' physical health management service. Through the student's physical health test on education intervention and exercise intervention, it is concluded that college students' physical health data sharing system based on the Django framework can cultivate students' interest in sports and improve their athletic ability and physical fitness.

\section{Introduction}

With the rapid development of China's economy and the continuous improvement of people's living standards, health problems have gradually become a common social problem in China [1]. College students play an important role in China's future construction and development, and their health problems are getting higher attention from schools, society, and families. At present, the health level of college students in China tends to decline overall. Therefore, it is necessary to improve the health level of college students [2]. The cultivation of students' sports consciousness, exercise habits, and abilities has been paid less attention to in colleges and universities of China, which makes students attach little importance to sports and less want to participate in physical exercise, presenting no help in improving students' physical quality [3]. In these cases, it is therefore necessary to establish a physical health data sharing system of college students to enhance students' sports participation and interest and to lead students to have good sports habits to lay the foundation for the lifelong sports concept of college students.
Wang [4] analyzed the process of online health information sharing, proposed that creditworthiness is the foundation for realizing online health information sharing from the aspect of individual perception, and constructed the credit file system based on the social credit system theory. The system consists of the credit files of enterprises, government, and individuals, which focuses on the target system and exchange system, defines main tasks including transmission, collection, and evaluation of credit data, and identifies the guarantee methods of the online health sharing system in terms of content, technology, and system. Following the national big data policies, Ruhua and Fangfang [5] proposed that China's government data be kept shared and open, and further clarified the relevant system using techniques such as inquiry policies. The results prove that China's government data opening and sharing policies have three levels: infrastructure level, government governance level, and data management level, which provide a policy framework for the further development of government data and clarify the direction. Guo and $\mathrm{Wu}$ [6] considered seven subordinate colleges in Wuhan City, for instance, made a profound investigation into the sharing system and supposed that it 
is exceptionally fundamental and plausible to fabricate a sharing component for actual well-being observing help of college understudies. What is more, the best area of the stage was the Wuhan University of Technology. The object was to give practical reference to the adapt, informatization, intellectualized, and effective development administration of college students' body well-being checking in China. van Panhuis et al. [7] led a deliberate systematic review of possible obstructions to general well-being information sharing. Reports that depicted boundaries to sharing regularly gathered general well-being information were qualified for consideration and investigated freely by a group of specialists. Zheng et al. [8] meant to build up a well-being-related information sharing framework by coordinating IoT to empower secure, charge less, alter safe, profoundly versatile, and granularly controllable well-being information trade, just as assemble a model and lead trials to confirm the attainability of the proposed arrangement. Bell et al. [9] talked with 70 solid volunteers to comprehend their decisions about how the data in their well-being record ought to be shared for research. Twenty-eight review addresses caught the individual inclinations of solid volunteers. The outcomes showed that respondents felt open to taking an interest in research in the event that they were given decisions about what parts of their clinical information would be shared and with whom that information would be shared. The outcomes recommend that straightforwardness during the time spent sharing is a significant factor in the choice to share clinical information for research. Tang et al. [10] planned an upgraded property-based encryption technique through the blend of an individual access strategy on patients and an expert access strategy on the haze hub for viable clinical benefit arrangement. Besides, a critical encryption utilization decrease was accomplished for patients by offloading a bit of the calculation and capacity trouble from patients to the haze hub. Execution assessments showed cost-proficient encryption calculation, stockpiling, and energy utilization. Conducting well-being experts' impression of granular information is concentrated by Grando et al. [11]. Semiorganized face-to-face meetings of 20 well-being experts were directed at two distinct locales. The subjective and quantitative examination was performed. This examination educates the conversation on creating innovation that helps balance supplier and patient information sharing and access needs. Maughan and Combe [12] provided a useful illustration of how a school area properly shares information with outside accomplices. It is a commonsense illustration of how to apply the standards found in the article on information sharing.

Based on the above research background, this paper applies the Django framework to the construction of college students' physical health data sharing system to promote the understanding of students' physical health status in schools and improve their physical health level.

The remainder of this paper is organized as follows. Section 2 presents the construction of college students' physical health data sharing system. Section 3 provides the analysis of the experiment. Section 4 concludes this paper with several remarks.

\section{Construction of College Students' Physical Health Data Sharing System}

2.1. Feasibility Analysis of the Construction of College Students' Physical Health Data Sharing System. The college students' physical health data sharing system is designed to promote the physical and mental health of college students. The data sharing system of college students' physical health mainly relies on colleges and universities' existing resources and platforms to manage and serve students' physical health [13]. At present, the school level hospital, the mental health center, and the physique test center are responsible for the management of students' physical health in colleges and universities in China. The college students' physical health data sharing system integrates these superior resources and platforms into a resource sharing platform for students. The college students' physical health data sharing system is developed to ensure better the physical fitness of college students [14]. The exercise intervention and health education intervention in the health intervention help students to establish a correct concept of health and sports, and require students to master a good scientific and reasonable physical exercise method and cultivate good exercise habits, enabling students to achieve healthy physical and mental development.

The construction of college students' physical health data sharing system has the following advantages.

(1) There is a good foundation for college students' physical health management [15]. The academic atmosphere and cultural environment of colleges and universities are conducive to promoting and constructing the college students' physical health data sharing system

(2) College students can easily accept new things [16]

(3) College students have certain cultural qualities, which makes it convenient for effective integration of sports and medical resources in colleges and universities to achieve complementary advantages

(4) The college students' physical health data sharing system can take advantage of physical education in universities [17]. Especially, improve the quality of education and train healthy students for teachers

In the college students' physical health data sharing system, the establishment of students' physical health files can rely on the existing database of college students' personal information in China. Each student has their file and physical health information database and can access personal academic information on the school website. Colleges and universities can provide assistance and support for the construction of students' personal physical health management files [18]. Students' health information including physique test results, mental health test results, and physical examination forms are entered into the database to form students' personal physical health management files. It is feasible for colleges and universities to establish students' personal physical health management files. 


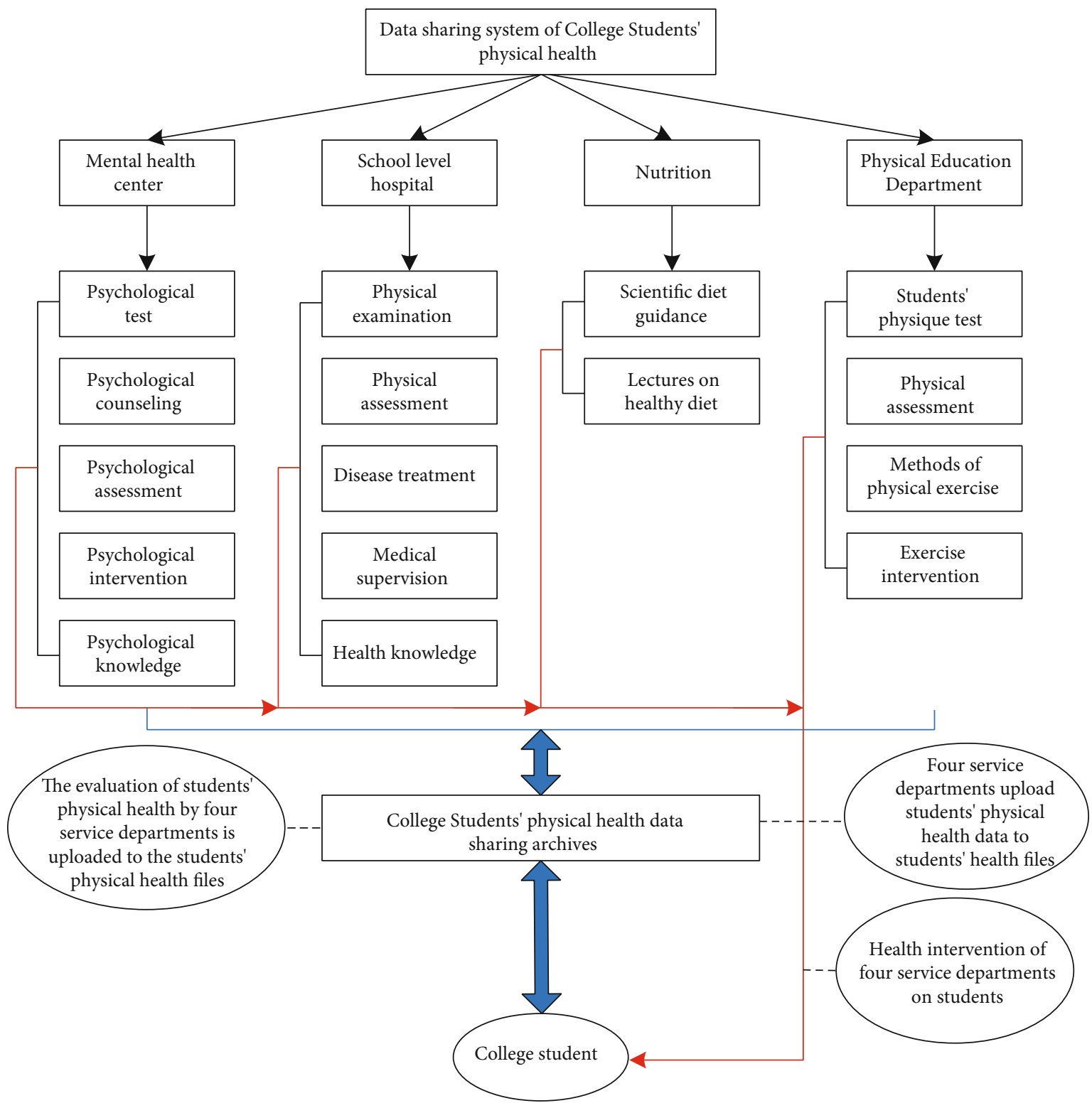

FIGURE 1: Organizational framework of students' physical health data sharing system.

In the college students' physical health data sharing system, the physical education department, school level hospital, and mental health center can analyze the physical health status of college students and discuss and make interventions. For example, the physical education department analyzes and evaluates students' physique test results and proposes different solutions for different students to intervene in their physique health according to their individual needs. Based on students' physical examination reports, the school level hospital diagnoses and treats students' physical diseases and provides targeted guidance for their rehabilitation [19]. The mental health center assesses the psychological status of students through psychological tests and intervenes and provides guidance on psychological disorders, including mental health lectures on common psychological disorders among students for prevention in advance. Nutrition involves instruction and publicity about a healthy diet to help students develop healthy eating habits.

\subsection{Construction Model of College Students' Physical Health}

Data Sharing System. The college students' physical health data sharing system connects departments associated with students' physical health in colleges and universities [20] and draws on the strengths of each department to achieve the sharing of students' physical health data. The construction of college students' physical health data sharing system requires the unified leadership of departments, such as the mental health center, the school level hospital, the physical education department, and the nutrition in colleges and universities, to strengthen the ability of each department to cooperate with each other. In this paper, by reviewing literature and books related to students' physical health, 


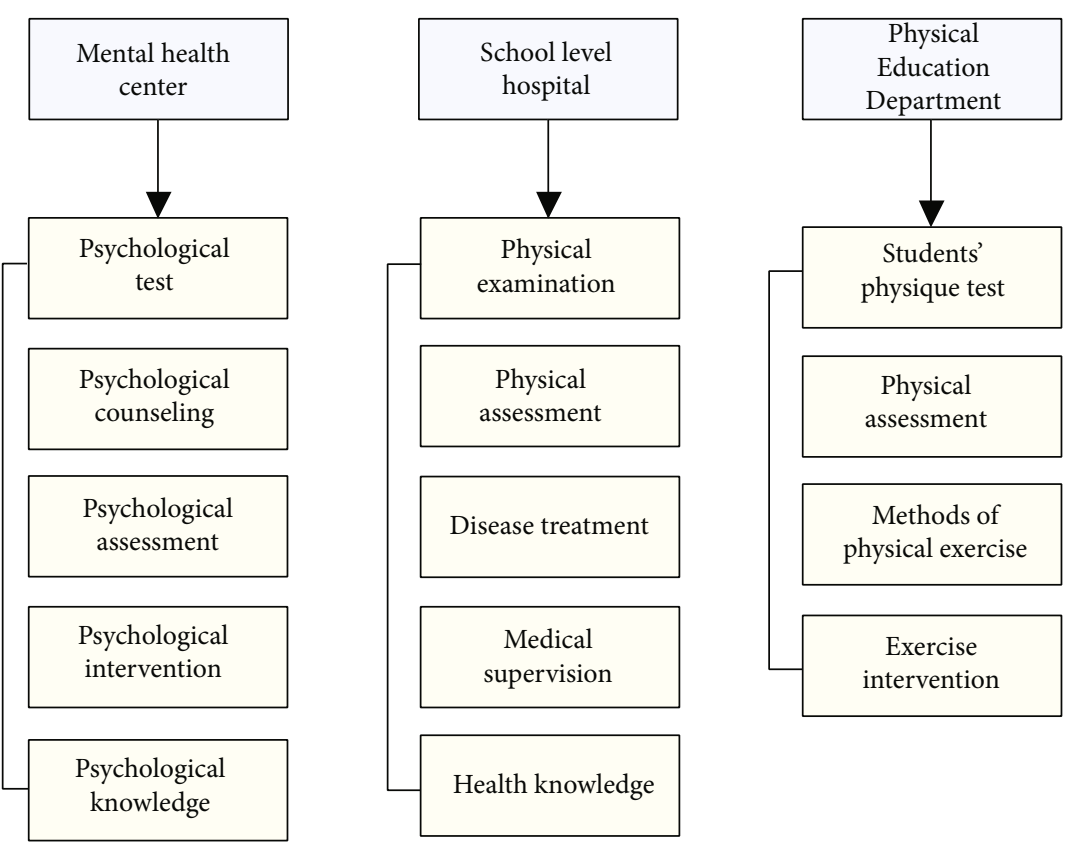

FIgure 2: Test college students' physical health status.

TABLE 1: $50 \mathrm{~m}$ sprint scale.

\begin{tabular}{lcccc}
\hline \multirow{2}{*}{ Grade } & \multicolumn{2}{c}{ Schoolboy } & \multicolumn{2}{c}{ Girl student } \\
& $\begin{array}{c}\text { Freshmen to } \\
\text { sophomores }\end{array}$ & $\begin{array}{c}\text { Junior to } \\
\text { senior }\end{array}$ & $\begin{array}{c}\text { Freshmen to } \\
\text { sophomores }\end{array}$ & $\begin{array}{c}\text { Junior to } \\
\text { senior }\end{array}$ \\
\hline Excellent & $\leq 6.7 \mathrm{~s}$ & $\leq 6.6 \mathrm{~s}$ & $\leq 7.5 \mathrm{~s}$ & $\leq 7.4 \mathrm{~s}$ \\
Good & $(6.7 \mathrm{~s}, 7.1 \mathrm{~s}]$ & $(6.6 \mathrm{~s}, 7.0 \mathrm{~s}]$ & $(7.5 \mathrm{~s}, 8.0 \mathrm{~s}]$ & $(7.4 \mathrm{~s}, 8.4 \mathrm{~s}]$ \\
Pass & $(7.1 \mathrm{~s}, 9.3 \mathrm{~s}]$ & $(7.0 \mathrm{~s}, 9.2 \mathrm{~s}]$ & $(8.0 \mathrm{~s}, 10.5 \mathrm{~s}]$ & $(8.4 \mathrm{~s}, 10.4 \mathrm{~s}]$ \\
Fail & $>9.3 \mathrm{~s}$ & $>9.2 \mathrm{~s}$ & $>10.5 \mathrm{~s}$ & $>10.4 \mathrm{~s}$ \\
\hline
\end{tabular}

combined with the Django framework and the actual situation of colleges and universities [21], the organizational framework of students' physical health data sharing system is constructed as shown in Figure 1.

The college students' physical health data sharing system should provide physical health management services for students from freshmen. The specific steps are as follows.

Step 1: Test college students' physical health status.

After freshmen enrollment, as shown in Figure 2, students' mental health data, physical health data, and physique data should first collect for the mental health center, the school level hospital, and the physical education department, which lays the foundation for students' physical health data sharing [22]. data.

Step 2: Collect and summarize students' physical health

Establish the personal physical health management files for each newly enrolled student, then summarize students' physical health information from the mental health center, the school level hospital, and the physical education department, and enter the information into the newly established student personal physical health management files.

Step 3: Analyze and evaluate college students' physical health data.
The mental health center, the school level hospital, and the physical education department in the data sharing system upload the results of analysis and scientific assessments on the detected students' personal physical health data by the professionals to the students' personal physical health management files.

Step 4: Conduct students' physical health guidance and intervention.

Develop approaches to students' physical health interventions based on the assessment results of each student's physical health data [23], to help students develop a healthy lifestyle and good physical exercise habits, improving the overall level of college students' physical health.

Improving students' physical health services by the college students' physical health data sharing system is a gradual process. After the above steps, it is necessary to test the students' physical health data again, update the students' personal physical health management files promptly, evaluate the completed updated student physical health files, and provide interventions and guidance to the students' physical health based on the evaluation results [24]. Through the testing and evaluation of college students' physical health data and the physical health intervention process, encourage students to establish the correct concept of health and improve their awareness and level of physical health.

\section{Experiment and Analysis}

3.1. Students' Physical Health Education Intervention. Through the social education activities in students' physical health education, students take behaviors and lifestyles that are beneficial to their physical health and eliminate risk factors that affect their physical health, which not only prevents diseases in advance but also promotes their physical health 
TABLE 2: $800 \mathrm{~m}$ race and $1000 \mathrm{~m}$ race scale.

\begin{tabular}{|c|c|c|c|c|}
\hline \multirow{2}{*}{ Grade } & \multicolumn{2}{|c|}{ Schoolboy } & \multicolumn{2}{|c|}{ Girl student } \\
\hline & Freshmen to sophomores & Junior to senior & Freshmen to sophomores & Junior to senior \\
\hline Excellent & $\leq 3^{\prime} 27^{\prime \prime}$ & $\leq 3^{\prime} 25^{\prime \prime}$ & $\leq 3^{\prime} 45^{\prime \prime}$ & $\leq 3^{\prime} 40^{\prime \prime}$ \\
\hline Good & $\left(3^{\prime} 27^{\prime \prime}, 3^{\prime} 42^{\prime \prime}\right]$ & $\left(3^{\prime} 27^{\prime \prime}, 3^{\prime} 40^{\prime \prime}\right)$ & $\left(3^{\prime} 45^{\prime \prime}, 4^{\prime} 00^{\prime \prime}\right]$ & $\left(3^{\prime} 40^{\prime \prime}, 3^{\prime} 55^{\prime \prime}\right)$ \\
\hline Pass & $\left(3^{\prime} 42^{\prime \prime}, 4^{\prime} 32^{\prime \prime}\right]$ & $\left(3^{\prime} 40^{\prime \prime}, 4^{\prime} 10^{\prime \prime}\right]$ & $\left(4^{\prime} 30^{\prime \prime}, 5^{\prime} 30^{\prime \prime}\right.$ & $\left(3^{\prime} 55^{\prime \prime}, 5^{\prime} 20^{\prime \prime}\right)$ \\
\hline Fail & $>4^{\prime} 32^{\prime \prime}$ & $>4^{\prime} 10^{\prime \prime}$ & $>5^{\prime} 30^{\prime \prime}$ & $>5^{\prime} 20^{\prime \prime}$ \\
\hline
\end{tabular}

TABle 3: Standing long jump scale.

\begin{tabular}{lcccc}
\hline Grade & \multicolumn{2}{c}{ Schoolboy } & & \multicolumn{2}{c}{ Girl student } \\
& Freshmen to sophomores & Junior to senior & Freshmen to sophomores & Junior to senior \\
\hline Excellent & $\geqq 2.63 \mathrm{~m}$ & $\geqq 2.65 \mathrm{~m}$ & $\geqq 1.95 \mathrm{~m}$ & $\geqq 1.96 \mathrm{~m}$ \\
Good & {$[2.48 \mathrm{~m}, 2.63 \mathrm{~m})$} & {$[2.40 \mathrm{~m}, 2.65 \mathrm{~m})$} & {$[1.81 \mathrm{~m}, 1.95 \mathrm{~m})$} & {$[1.82 \mathrm{~m}, 1.96 \mathrm{~m})$} \\
Pass & {$[2.08 \mathrm{~m}, 2.48 \mathrm{~m})$} & {$[2.10 \mathrm{~m}, 2.40 \mathrm{~m})$} & {$[1.51 \mathrm{~m}, 1.81 \mathrm{~m})$} & {$[1.55 \mathrm{~m}, 1.82 \mathrm{~m})$} \\
Fail & $<2.08 \mathrm{~m}$ & $<2.10 \mathrm{~m}$ & $<1.51 \mathrm{~m}$ & $<1.55 \mathrm{~m}$ \\
\hline
\end{tabular}

and improves their quality of life [25]. The core of students' physical health education is to help students develop an active awareness of physical health, change poor behaviors and lifestyles, understand behaviors that can affect their physical health, and consciously choose behaviors and lifestyles that are beneficial to their physical health.

3.2. Sports Intervention. As an important part of students' physical health intervention, sports intervention is realized by guiding students to perform physical exercise. Introducing the college students' physical health data sharing system to colleges and universities to realize students' physical health data sharing helps the implementation of sports intervention, improves the effect of sports intervention, and plays an important role in students' physical health intervention.

3.2.1. Students' Speed Quality Exercise. Students' speed quality refers to the ability of the human body to move quickly, which can reflect the ability of movement acceleration and a maximum speed of the human body [26]. The test programs of speed quality are mainly reflected in the $50 \mathrm{~m}$ sprint, and the test scale is shown in Table 1.

From Table 1, a sports program with strong explosive power and high speediness is suitable to train students' speed quality. In college students' physical health management training, the intensity, duration, and interval should be controlled according to the actual situation of the students, and stretching exercises should be done after the training to help students recover.

3.2.2. Students' Endurance Quality Exercise. Endurance quality refers to the ability of the human body to maintain a specific movement quality and intensity load for a certain period of time [27]. It is often tested in the 800-meter race and $1000 \mathrm{~m}$ race and is associated with the lung capacity of students. Therefore, students' middle-distance race training can improve their cardiorespiratory fitness. The 800-meter race and $1000 \mathrm{~m}$ race scale is shown in Table 2 .
From Table 2, students' endurance quality intervention and guidance should consider student s' interest and hobbies in sports and choose a program that will help students aerobically exercise. Improving students' endurance quality requires constant accumulation in physical exercise activities, including students' active participation in physical exercise and persistence.

3.2.3. Students' Strength Quality Exercise. Strength quality refers to the ability of the human body to overcome internal and external resistance when working [28]. It is mainly tested in the standing long jump, boys pull up and girls sit up. The standing long jump can test students' lower limb strength and core strength, pull up can test students' upper limb strength, and sit up can test students' core strength of the waist and abdomen. The test scales for the three programs are shown in Tables 3 and 4.

The standing long jump training should focus on improving students' lower limb strength and core strength and teach students the correct method of standing long jump, including deep squat and frog jump. The boys pull up should combine with swimming, basketball, volleyball, and other upper limb loading programs to improve students' upper limb strength. The girls sit up focuses on a flat support, which improves students' waist and abdominal strength for physical health intervention.

In the strength training of students, the intensity and amount need to be adjusted according to the physical quality of each student to ensure the proper amount of student training and to achieve the best strength training results.

3.2.4. Students' Flexible Quality Exercise. Flexible quality refers to the range of motion of the human body's joints and the ability to stretch the soft tissues [29]. It is mainly tested in the sit and reach program, which requires students to sit in front of a tester, straighten their legs, and push the 
Table 4: Pull up and sit up scale (times).

\begin{tabular}{lcccc}
\hline Grade & \multicolumn{2}{c}{ Boys pull up } & \multicolumn{2}{c}{ Girls sit ups } \\
& $\begin{array}{c}\text { Freshmen to } \\
\text { sophomores }\end{array}$ & $\begin{array}{c}\text { Junior to } \\
\text { senior }\end{array}$ & $\begin{array}{c}\text { Freshmen to } \\
\text { sophomores }\end{array}$ & $\begin{array}{c}\text { Junior to } \\
\text { senior }\end{array}$ \\
\hline Excellent & $\geqq 17$ & $\geqq 18$ & $\geqq 52$ & $\geqq 53$ \\
Good & {$[15,17)$} & {$[16,18)$} & {$[46,52)$} & {$[47,53)$} \\
Pass & {$[9,15)$} & {$[10,16)$} & {$[26,46)$} & {$[26,47)$} \\
Fail & $<9$ & $<10$ & $<25$ & $<26$ \\
\hline
\end{tabular}

TABLE 5: Sit and reach scale.

\begin{tabular}{lcccc}
\hline \multirow{2}{*}{ Grade } & \multicolumn{2}{c}{ Schoolboy } & \multicolumn{2}{c}{ Girl student } \\
& $\begin{array}{c}\text { Freshmen to } \\
\text { sophomores }\end{array}$ & $\begin{array}{c}\text { Junior to } \\
\text { senior }\end{array}$ & $\begin{array}{c}\text { Freshmen to } \\
\text { sophomores }\end{array}$ & $\begin{array}{c}\text { Junior to } \\
\text { senior }\end{array}$ \\
\hline Excellent & $\geqq 21.3$ & $\geqq 21.5$ & $\geqq 22.2$ & $\geqq 22.4$ \\
Good & $\geqq 17.7$ & $\geqq 18.2$ & $\geqq 19.0$ & $\geqq 19.5$ \\
Pass & $\geqq 3.7$ & $\geqq 4.2$ & $\geqq 6.0$ & $\geqq 6.5$ \\
Fail & $\leqq 3.6$ & $\leqq 4.1$ & $\leqq 5.9$ & $\leqq 6.5$ \\
\hline
\end{tabular}

TABLE 6: Weight of single indexes in students' physical health test.

\begin{tabular}{lccc}
\hline Entry name & Proportion & Entry name & Proportion \\
\hline Body mass index & $15 \%$ & Standing long jump & $10 \%$ \\
Vital capacity & $15 \%$ & Pull up/sit ups & $10 \%$ \\
50-meter race & $20 \%$ & $1000 \mathrm{~m} / 800 \mathrm{~m}$ & $20 \%$ \\
Sit and lie forward & $10 \%$ & & \\
\hline
\end{tabular}

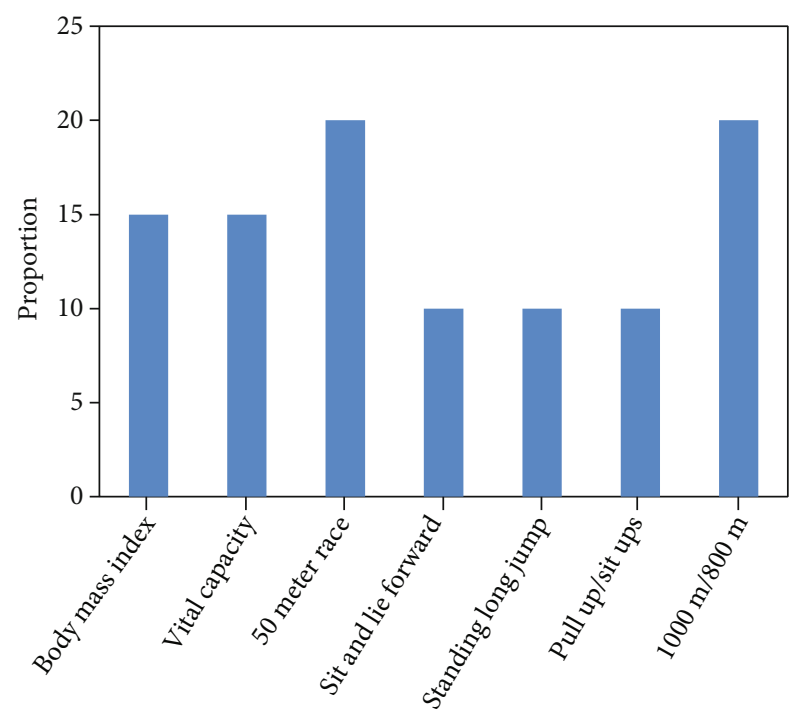

FIGURE 3: Weights of single indexes.

instrument with both arms to obtain the test results. The sit and reach scale is shown in Table 5 .

Students' flexible quality exercise should combine with other sports programs such as yoga to enhance the whole body's flexibility by stretching. This program requires a long period of continuous stretching exercise, combined with speed, endurance, and strength training, to improve students' physical health.

\subsection{Results and Analysis}

3.3.1. Experiment Results. Forty-six students participated in the students' physical health training, 23 in the experiment group, and 23 in the intervention group, and the number of effective training in the experiment group was 22, with one invalid.

The number of physical exercise instruction hours during the experiment was 18, and the specific time was based on the students' spare time. Only one student was absent from the 18-hour physical exercise instruction due to physical reasons, and all other students completed all the training programs. This shows that students are highly motivated to physical health training and pay great attention to their physical health.

3.3.2. Analysis on the Comparative Results of the Individual Program Scores in Students' Physical Health Test. The weight of each single program score in students' physical health test is shown in Table 6.

From the results in Table 6, it can be seen that students attach more importance to speed quality and endurance quality training, and there is a correlation between lung capacity and speed quality training, which obviously shows the importance of endurance quality. The results are also shown in Figure 3 for a better comparison.

According to Figure 3, more programs in endurance should be arranged in the training as much as possible to improve students' physique test performance while raising students' physical health quality in other aspects.

\section{Conclusion}

This paper puts forward the construction of the physical health data sharing system based on the Django framework. By analyzing the feasibility of constructing the data sharing system of college students' physical health, this paper constructs the data sharing system. The results show that the data sharing system of college students' physical health based on Django framework can improve students' physical health.

\section{Data Availability}

The labeled datasets used to support the findings of this study are available from the corresponding author upon request.

\section{Conflicts of Interest}

The authors declare no competing interests.

\section{Acknowledgments}

This study was supported by the 2018 Tianjin Philosophy and Social Science Planning Funding Project: Construction 
of University Sports Health Management System and Funding for Sports (TJTY18-018).

\section{References}

[1] M. Yang and Y. Yang, "An efficient hybrid peer-to-peer system for distributed data sharing," IEEE Transactions on Computers, vol. 59, no. 9, pp. 1158-1171, 2010.

[2] J. Sun, H. Xiong, S. Zhang, X. Liu, J. Yuan, and R. H. Deng, “A secure flexible and tampering-resistant data sharing system for vehicular social networks," IEEE Transactions on Vehicular Technology, vol. 69, no. 11, pp. 12938-12950, 2020.

[3] E. M. Godfrey, I. I. West, J. Holmes, G. A. Keppel, and L. M. Baldwin, "Use of an electronic health record data sharing system for identifying current contraceptive use within the WWAMI region practice and research network," Contraception, vol. 98, no. 6, pp. 476-481, 2018.

[4] W. Wang, "Research on the construction of credit file system based on online health information sharing," In Chinese, Journal of Modern Information, vol. 38, no. 12, pp. 111-115, 2018.

[5] H. Ruhua and W. Fangfang, "The policy framework and content of my country's government data open sharing: content analysis of policy texts at the national level," In Chinese, Library and Information Work, no. 9, pp. 5-13, 2018.

[6] M. Guo and Y. Wu, "Construct sharing mechanism of college students' physical health monitoring service based on geographic information system," In International Conference on Machine Learning and Big Data Analytics for IoT Security and Privacy, 2020, pp. 772-778, Springer, Cham, 2020.

[7] W. G. van Panhuis, P. Paul, C. Emerson et al., "A systematic review of barriers to data sharing in public health," BMC Public Health, vol. 14, no. 1, pp. 1-9, 2014.

[8] X. Zheng, S. Sun, R. R. Mukkamala, R. Vatrapu, and J. Ordieres-Meré, "Accelerating health data sharing: a solution based on the Internet of Things and distributed ledger technologies," Journal of Medical Internet Research, vol. 21, no. 6, article e13583, 2019.

[9] E. A. Bell, L. Ohno-Machado, and M. A. Grando, "Sharing my health data: a survey of data sharing preferences of healthy individuals," AMIA Annual Symposium Proceedings, vol. 2014, p. 1699, 2014.

[10] W. Tang, J. Ren, K. Zhang, D. Zhang, Y. Zhang, and X. S. Shen, "Efficient and privacy-preserving fog-assisted health data sharing scheme," ACM Transactions on Intelligent Systems and Technology (TIST), vol. 10, no. 6, pp. 1-23, 2019.

[11] A. Grando, J. Ivanova, M. Hiestand et al., "Mental health professional perspectives on health data sharing: mixed methods study," Health Informatics Journal, vol. 26, no. 3, pp. 20672082, 2020.

[12] E. D. Maughan and L. G. Combe, "Data sharing: partnering with others to advance student health," NASN School Nurse, vol. 34, no. 4, pp. 214-215, 2019.

[13] A. J. Holmgren and E. W. Ford, "Assessing the impact of health system organizational structure on hospital electronic data sharing," Journal of the American Medical Informatics Association, vol. 25, no. 1, p. 10628, 2018.

[14] C. Park, "Parameter estimation from load-sharing system data using the expectation-maximization algorithm," IIE Transactions, vol. 45, no. 2, pp. 147-163, 2013.

[15] R. Larsen, T. Holmern, S. D. Prager, H. Maliti, and E. Røskaft, "Using the extended quarter degree grid cell system to unify mapping and sharing of biodiversity data," African Journal of Ecology, vol. 46, no. 3, pp. 382-392, 2009.

[16] M. Cocca, D. Giordano, M. Mellia, and L. Vassio, "Free floating electric car sharing: a data driven approach for system design," IEEE Transactions on Intelligent Transportation Systems, vol. 20, no. 12, pp. 4691-4703, 2019.

[17] F. Khazalah, Z. Malik, and A. Rezgui, “Automated conflict resolution in collaborative data sharing systems using community feedbacks," Information Sciences, vol. 298, pp. 407-424, 2015.

[18] Z. Pervez, A. M. Khattak, S. Lee, and Y. K. Lee, "SAPDS: selfhealing attribute-based privacy aware data sharing in cloud," Journal of Supercomputing, vol. 62, no. 1, pp. 431-460, 2012.

[19] J. R. Vest and L. M. Issel, "Factors related to public health data sharing between local and state health departments," Health Services Research, vol. 49, pp. 373-391, 2014.

[20] D. E. Conroy, J. P. Maher, S. Elavsky, A. L. Hyde, and S. E. Doerksen, "Sedentary behavior as a daily process regulated by habits and intentions," Health Psychology, vol. 32, no. 11, p. 1149, 2013.

[21] P. Zarcone, D. Nordenberg, M. Meigs, U. Merrick, D. Jernigan, and S. H. Hinrichs, "Community-driven standards-based electronic laboratory data-sharing networks," Public Health Reports, vol. 125, no. 2, pp. 47-56, 2010.

[22] S. Rosenbaum, "Data governance and stewardship: designing data stewardship entities and advancing data access," Health Services Research, vol. 45, no. 5, pp. 1442-1455, 2010.

[23] Y. Lyu, V. C. S. Lee, K. Y. Ng, B. Y. Lim, K. Liu, and C. Chen, "Flexi-sharing: a flexible and personalized taxi-sharing system," IEEE Transactions on Vehicular Technology, vol. 68, no. 10, pp. 9399-9413, 2019.

[24] Y. Hu, Y. Zhang, D. Lamb, M. Zhang, and P. Jia, "Examining and optimizing the BCycle bike-sharing system - a pilot study in Colorado, US," Applied Energy, vol. 247, pp. 1-12, 2019.

[25] K. N. Genikomsakis, I. A. Gutierrez, D. Thomas, and C. S. Ioakimidis, "Simulation and design of fast charging infrastructure for a university-based e-carsharing system," IEEE Transactions on Intelligent Transportation Systems, vol. 19, no. 9, pp. 2923 2932, 2018.

[26] L. Lin, H. Ma, and Z. Bai, "An improved proportional loadsharing strategy for meshed parallel inverters system with complex impedances," IEEE Transactions on Power Electronics, vol. 32, no. 9, pp. 7338-7351, 2017.

[27] X. Qiu and J. S. L. Lam, “The value of sharing inland transportation services in a dry port system," Transportation Science, vol. 52, no. 4, pp. 835-849, 2018.

[28] S. C. Oh and J. Shin, “A semantic e-Kanban system for network-centric manufacturing: technology, scale-free convergence, value and cost-sharing considerations," International Journal of Production Research, vol. 50, no. 19, pp. 52925316, 2012.

[29] J. H. Lin and S. H. Cheng, "The impact of a medication record sharing program among diabetes patients under a single-payer system: the role of inquiry rate," International Journal of Medical Informatics, vol. 116, pp. 18-23, 2018. 